Aksaray University
Journal of Science and Engineering
e-ISSN: 2587-1277
http://dergipark.gov.tr/asujse
http://asujse.aksaray.edu.tr

Research Article

\title{
Electronic Structure and Binding Energy of Spherical Quantum Dot
}

\author{
Fatma Yilmazer ${ }^{1}$, Yusuf Yakar, ${ }^{1,}$, Bekir Cakir ${ }^{2}$, Ayhan Ozmen ${ }^{2}$ \\ ${ }^{1}$ Physics Department, Faculty of Arts and Science, Aksaray University, Campus 68100, Aksaray Turkey \\ ${ }^{2}$ Physics Department, Faculty of Science, Selcuk University, Campus 42075, Konya Turkey
}

-Received Date: 30 Mar 2017

Revised Date: 20 Apr 2017

-Accepted Date: 21 Apr 2017

-Published Online: 03 May 2017

\begin{abstract}
In this study, we have calculated the energy states and the wavefunctions of the spherical quantum dot with finite and infinite confining potential. In addition, we have investigated the binding energies of the ground and excited states of the spherical quantum dot as a function of dot radius. In order to calculate the energy eigenvalues and the wavefunctions Quantum Genetic Algorithm and Hartre-Fock Roothaan method have been employed. The results show that dot radius and confinement potential has a great effect on the energy states and binding energies. In large dot radii, the effect of confinement potential on energy states is disappeared and energy states go to the energy values of hydrogen atom.
\end{abstract}

\section{Keywords}

Spherical Quantum Dot, Binding Energy, Confining Potential

*Corresponding Author: Yusuf Yakar, yuyakar@yahoo.com 


Aksaray University
Journal of Science and Engineering
e-ISSN: 2587-1277
http://dergipark.gov.tr/asujse
http://asujse.aksaray.edu.tr

Research Article

\title{
Küresel Kuantum Nokta Yapının Elektronik Yapısı ve Bağlanma Enerjisi
}

\author{
Fatma Yılmazer ${ }^{1}$, Yusuf Yakar, ${ }^{1, *}$, Bekir Çakır², Ayhan Özmen² \\ ${ }^{1}$ Aksaray Üniversitesi, Fen Edebiyat Fakültesi, Fizik Bölümü, 68100 Aksaray, Türkiye \\ ${ }^{2}$ Selçuk Üniversitesi, Fen Fakültesi, Fizik Bölümü, 42075 Konya, Türkiye
}

-Gönderi Tarihi: 30 Mar 2017

Dïzeltme Tarihi: 20 Nis 2017

-Kabul Tarihi: 21 Nis 2017

-Çevrimiçi Yayın Tarihi: 03 May 2017

\section{Özet}

$\mathrm{Bu}$ çalışmada sonlu ve sonsuz sınırlandırıcı potansiyele sahip küresel kuantum nokta yapının taban ve bazı uyarılmış enerji seviyeleri ve dalga fonksiyonları hesaplandı. Bununla beraber taban ve çeşitli uyarılmış durumlarının bağlanma enerjileri nokta yapının yarıçapına bağlı olarak incelendi. Enerji öz değerlerini ve öz fonksiyonlarını hesaplamak için Kuantum Genetik Algoritma ve Hartree-Fock Roothaan metodu kullanılmıştır. Sonuçlar göstermiştir ki kuantum nokta yapının enerji seviyeleri üzerinde yarıçapın ve sınırlandırıcı potansiyelin büyük etkisi vardır. Buna karşılık büyük nokta yarıçaplarında sınırlandırıcı potansiyelin etkisinin ortadan kalktığı ve enerji seviyelerinin hidrojen atomunun değerlerine gittiği görüldü.

\section{Anahtar Kelimeler}

Küresel Kuantum Nokta Yapı, Bağlanma Enerjisi, Sınırlandırma Potansiyeli

*Sorumlu Yazar: Yusuf YAKAR, yuyakar@yahoo.com 


\section{GİRIŞ}

Modern teknolojideki olağanüstü gelişmeler sayesinde kuantum tel, kuantum kuyu ve kuantum nokta gibi nanometre boyutundaki düşük boyutlu yapıları üretmek mümkün hale gelmiştir. Düşük boyutlu yapıların elektronik ve optiksel özellikleri, yük taşıyıcılarının sayısı ve tipleri gibi parametreleri modifiye edilmek suretiyle önemli ölçüde değiştirilebilir. Düşük boyutlu yapılar arasında kuantum nokta yapılar mikro-elektronik ve opto-elektronik cihazlardaki potansiyel uygulamalarından dolayı oldukça fazla ilgi çekmektedir. Kuantum nokta yapılarda yük taşıyıcıları (elektron ve deşikler) üç boyutta sınırlandırılmıştır. Yük taşıyıcılarının uzaysal sınırlandırılması sistemde kesikli enerji seviyeleri ve kabuklu yapılar gibi eşsiz özelliklerin oluşmasına neden olmaktadır. Bu özelliklerin atomlara ait olması nedeniyle, kuantum nokta yapılar sık sık 'yapay atomlar' olarak da adlandırılır [1]. Kuantum nokta yapıların elektronik ve optiksel özelliklerinin değişmesine neden olan diğer bir etki de safsızlığın (impurity) olmasıdır. Safsızlık kuantum nokta yapının enerji dağılımında önemli değişikliğe neden olmakta ve optiksel özelliklerinin kontrol edilmesine imkân sağlamaktadır. Bütün bu nedenlerden dolayı son 10 yılda çeşitli araştırmacılar tarafından kuantum nokta yapıların elektronik yapısı [2-6], bağlanma enerjisi [7-10], optiksel [11-18] ve diğer özellikleri [19-22] gibi çeşitli parametreleri yoğun olarak çalışılmaktadır. Yukarıda belirtilen çalışmalar arasında Çakır ve ark. [2-5] sonlu ve sonsuz sınırlandırıcı potansiyele sahip bir ve iki elektronlu küresel kuantum nokta yapıların elektronik özelliklerini incelediler. Bose ve Sarkar [7] yüzeysel hidrojenik safsızlığın bağlanma enerjisini varyasyonel ve pertürbasyon yöntemiyle sonlu sinırlandırıcı potansiyel için hesapladılar. Porras-Montenegro ve Perez- Merchancano [9] hidrojenik safsızlığın taban durum enerjisini ve bağlanma enerjisini kuantum nokta yarıçapının fonksiyonu olarak farklı kuyu derinlikleri için çalıştılar. Yakar ve ark. [11-13] sonlu ve sonsuz sınırlandırıcı potansiyele sahip kuantum nokta yapıların çeşitli optiksel özelliklerini kuantum nokta yarıçapının fonksiyonu olarak hesapladılar. Onlar hesaplamalarında etkin kütle yaklaşımında modifiye edilmiş varyasyonel yöntemi kullandılar. Kasapoğlu ve ark. [16] elektrik ve manyetik alanın basamak şeklindeki kuantum nokta yapının optiksel özelliklerine olan etkisini incelediler. Bunların yanında Yeşilgül ve ark. [18] etkin kütle yaklaşımında kuantum telde manyetik alan, hidrostatik basınç ve sıcaklığın lineer ve nonliner optiksel özelliklere olan etkilerini incelerken, Mandal ve ark. [16] soğurma katsayıları üzerine manyetik alanın etkisini çalıştılar. Yakar ve ark. [19] merkezinde hidrojenik safsızlık olan sonlu ve sonsuz sınırlandırıcı potansiyele sahip kuantum nokta yapının aşırı ince yapı sabitlerini hesapladılar. 
Bu çalışmada sonlu ve sonsuz sınırlandırıcı potansiyele sahip küresel kuantum nokta yapıların taban ve çeşitli uyarılmış durumlarının enerji seviyeleri ve dalga fonksiyonları kuantum nokta yarıçapının fonksiyonu olarak elde edildi. Buna bağlı olarak kuantum nokta yapıların taban ve uyarılmış durumlara ait bağlanma enerjileri hesaplandı. Enerji seviyeleri ve dalga fonksiyonların elde edilmesinde Kuantum Genetik Algoritma (KGA) ve Hartree-Fock Roothaan (HFR) metodu kullanıld1.

\section{TEORI VE TANIMLAR}

Etkin kütle yaklaşımında, sonlu ve sonsuz sınırlandırıcı potansiyele sahip merkezinde safsızlık olan küresel kuantum nokta yapı göz önüne alınırsa, böyle bir sistemin Hamiltoniyeni atomik birimlerde aşağıdaki gibi verilir:

$$
H=-\frac{\hbar^{2} \nabla^{2}}{2 m^{*}}-\frac{Z}{\varepsilon_{r} r}+V_{c}(r)
$$

Burada Z safsızlığın yükü, r elektron ve safsızlık arasındaki uzaklık, m* elektronun etkin kütlesi ve $\varepsilon_{\mathrm{r}}$ de ortamın bağıl elektriksel geçirgenliğidir. $V_{c}(r)$ terimi ise küresel sınırlandırıcı potansiyeldir ve onun şekli sonsuz sınırlandırıcı potansiyel olması durumunda $V(r)=0$ için $r \leq R$ ve $V(r)=\infty$ için $r>R$ şeklinde olurken, sonlu sınırlandırıcı durumunda ise $V(r)=0$ için $r \leq R$ ve $V(r)=V_{0}$ için $r>R$ şeklindedir. Burada $\mathrm{R}$ kuantum noktanın yarıçapı ve $V_{0}$ da potansiyel yüksekliğidir. Denklem (1)'de eşitliğin sağ tarafındaki birinci terim elektronun kinetik enerjisini, ikinci terim elektron-safsızlık potansiyel enerjisini ve üçüncü terimde sınırlandırıcı potansiyeli göstermektedir.

HFR yaklaşımında, tek elektron dalga fonksiyonlarının uzaysal kısmı Slater tipi orbitallerin (STOs) lineer kombinasyonu şeklinde aşağıdaki gibi yazılabilir:

$$
\psi_{i}=\sum_{k=1}^{\sigma} c_{i k} \chi_{i k}\left(\zeta_{i k}, \vec{r}\right)
$$

Burada $k=n \ell m$ baz fonksiyonlarının kuantum sayıları, $\sigma$ baz seti sayısı, $c_{i k}$ açılım katsayıları ve $\zeta_{i k}$ de perdeleme sabitidir. Normalize olmamış kompleks STO, $\chi_{i k}$, nun genel formu

$$
\chi_{n \ell m}(\zeta, \vec{r})=r^{n-1} e^{-\zeta r} Y_{\ell m}(\theta \phi)
$$

ile verilir. Burada $Y_{\ell m}(\theta \phi)$ Condon-Shortly fazında kompleks küresel harmonik fonksiyondur. Denklem (1)'de verilen Hamiltoniyen için zamandan bağımsız Scrödinger denklemi aşağıdaki gibidir:

$$
H \psi_{i}=E_{i} \psi_{i}
$$


Burada $E_{i}$ ve $\psi_{i}$ Hamiltoniyen operatörünün özdeğer enerjisi ve özfonksiyonudur. Kuantum nokta yapının $E_{i}$ enerjisi ve $\psi_{i}$ özfonksiyonu modifiye olmuş varyasyonel yöntemle KGA ve HFR nin birleşimi olan metod kullanılarak hesaplanacaktır. Bu metodun detayları [2, 3] referanslarında verilmiştir. Denklem (1), (2) ve (3), Denklem (4)'te yerine konulursa STO'lar cinsinden kinetik enerjinin beklenen değeri

$$
<T>=\int_{0}^{R} \psi_{i}^{*}(\vec{r})\left(\frac{-\nabla^{2}}{2 m^{*}}\right) \psi_{j}(\vec{r}) d^{3} r=\sum_{n l m}^{\sigma} \sum_{n^{\prime} l^{\prime} m^{\prime}}^{\sigma} c_{n^{\prime} l^{\prime} m^{\prime}}^{*} c_{n l m}\left\langle\chi_{n^{\prime} l^{\prime} m^{\prime}}\left|-\frac{\nabla^{2}}{2 m^{*}}\right| \chi_{n l m}\right\rangle
$$

elektron-safsızlık etkileşim potansiyel enerjisinin beklenen değeri

$$
<V>=\int_{0}^{R} \psi_{i}^{*}(\vec{r}) \frac{-2}{r} \psi_{j}(\vec{r}) d^{3} r=\sum_{n l m}^{\sigma} \sum_{n^{\prime} l^{\prime} m^{\prime}}^{\sigma} c_{n^{\prime} l^{\prime} m^{\prime}}^{*} c_{n l m}\left\langle\chi_{n^{\prime} l^{\prime} m^{\prime}}\left|-\frac{Z}{\varepsilon_{r} r}\right| \chi_{n l m}\right\rangle
$$

ve sonlu sınırlandırıcı potansiyel enerjisinin beklenen değeri

$$
\left\langle V_{c}(r)>=\int_{0}^{R} \psi_{i}^{*}(\vec{r}) V_{c}(r) \psi_{i}(\vec{r}) d^{3} r=\sum_{n l m}^{\sigma} \sum_{n^{\prime} l^{\prime} m^{\prime}}^{\sigma} c_{n^{\prime} l^{\prime} m^{\prime}}^{*} c_{n l m}\left\langle\chi_{n^{\prime} l^{\prime} m^{\prime}}\left|V_{0}\right| \chi_{n l m}\right\rangle\right.
$$

ile verilir.

\section{TARTIŞMAVE SONUÇLAR}

$\mathrm{Bu}$ çalışmada merkezinde bir safsızlık olan sonlu ve sonsuz sınırlandırıcı potansiyel sahip küresel bir kuantum nokta yapının, GaAs/ $\mathrm{Al}_{\mathrm{x}} \mathrm{Ga}_{1-\mathrm{x}} \mathrm{As}$, taban ve çeşitli uyarılmış durumlarının enerji seviyeleri ve dalga fonksiyonları hesaplandı. Buradan hareketle yine kuantum nokta yapının taban ve uyarılmış durumlara ait bağlanma enerjileri hesaplandı. Hesaplamalarda malzeme olarak kuyu bölgesinde GaAs'nin malzeme parametreleri ve kuyu dişında $\mathrm{Al}_{x} \mathrm{Ga}_{1-}$ ${ }_{x}$ As'nin malzeme parametreleri kullanıldı. Burada $x$ alüminyum katkılanma oranı veya stokiyometrik orandır (stoichiometric ratio). GaAs ve $\mathrm{Al}_{x} \mathrm{Ga}_{1-x} \mathrm{As}$ 'nin bant aralıkları arasındaki fark $\Delta E_{g}(x)=\left(1.155 x+0.37 x^{2}\right) \mathrm{eV}$, etkin dielektrik sabiti $\varepsilon(x)=(13.18-3.12 x)$ ve elektronun etkin kütlesi $m(x)=(0.0665+0.0835 x) m_{0}$ olarak alınmıştır; burada $m_{0}$ serbest elektron kütlesidir. Hesaplamalarımızda Ref. [23]'te önerildiği gibi sınırlandırıcı potansiyelin büyüklüğünü belirlemek için bant aralığı farkının \%60’ını kullandık. Yukarıda verilen $\operatorname{GaAs}(x=0)$ 'ın parametreleri kullanılarak herhangi biri etkin Bohr yarıçapı ve etkin Rydberg enerjisini $\cong 101 \AA$ ve $\cong 5.72 \mathrm{meV}$ olarak hesaplayabilir.

Küresel kuantum nokta yapıların kuantum mekaniksel analizinde STO'lar tercih edilmiştir. Çünkü bu baz setlerinin elektronik dalga fonksiyonları çekirdeğe çok yakın ve çok uzak bölgelerde daha gerçekçi davranış sergilemektedir. Böylece biz $s$ (veya $p, d$ ve $f$ ) tipi atomik orbitaller için farklı perdeleme sabitlerine sahip $s$ (veya $p, d$ ve $f$ ) STO'ların lineer 
kombinasyonunu seçtik. Orbitalin ortogonalliğini oluşturmak için, aynı açısal momentuma sahip tek elektron dalga fonksiyonların tümünde aynı perdeleme parametrelerinin seti kullanıldı. Enerjinin beklenen değerini hesaplamak için sonlu sınırlandırıcı potansiyelde 7, sonsuz sınırlandırıcı potansiyelde 5 tane baz seti kullanılmıştır. Her bireyin orbital seti GrammSchmidt prosedürüne göre ortonormalize edilmiştir.

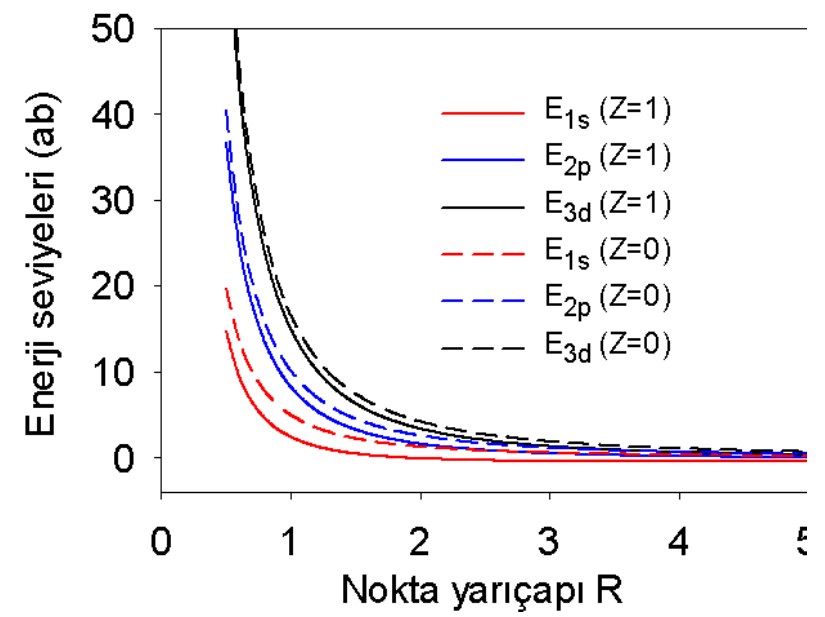

Şekil 1. Nokta yarıçapının fonksiyonu olarak merkezinde safsızlık olan $(Z=1$, sürekli çizgi) ve safsızlık olmayan ( $\mathrm{Z}=0$, kesikli çizgi) küresel kuantum nokta yapının enerji seviyeleri

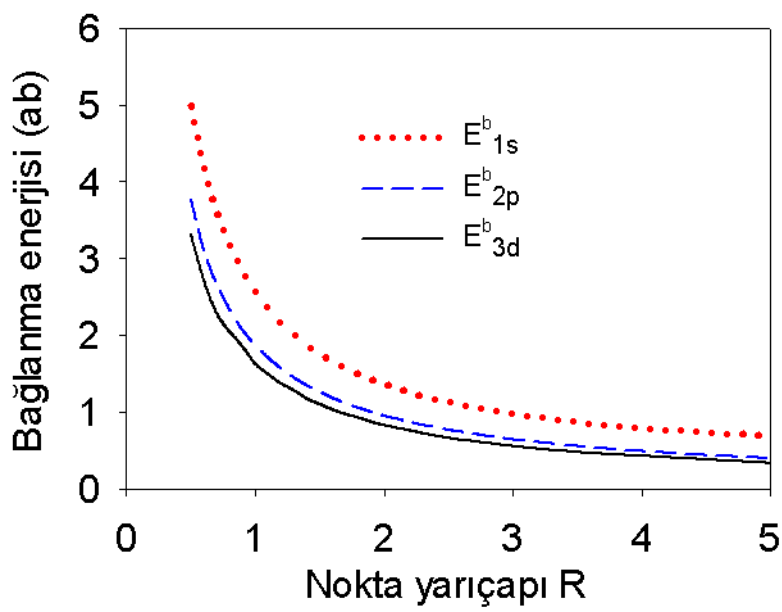

Şekil 2. Nokta yarıçapının fonksiyonu olarak küresel kuantum nokta yapının bağlanma enerjileri

Şekil 1'de küresel kuantum nokta yapının taban ve çeşitli uyarılmış durumlarına ait enerji seviyelerinin grafiğini nokta yarıçapının fonksiyonu olarak çizildi. Şekilden görüleceği gibi nokta yarıçapı artarken enerji seviyeleri monotonik olarak azalmaktadır. Daha büyük nokta yarıçaplarına gidildiğinde enerjilerin sabit değere gittiği görülmektedir. Küçük nokta yarıçaplarına giderken, $R \rightarrow 0$, enerjinin hızlı bir şekilde ıraksadığı görülmektedir. Bu durum nokta yarıçapının uzaysal etkisini yani sınırlandırma etkisini göstermektedir. Heisenberg ilkesine göre bu bölgede nokta yarıçapının değeri azalırken elektronun kinetik enerjisi artmakta ve bu da sistemin toplam enerjisini pozitif olarak büyütmektedir. Şekil 1'de Z=1 durumundaki enerji seviyelerinin diğerlerinden daha küçük olduğu görülmektedir. Bunun fiziksel nedeni, $\mathrm{Z}=1$ durumunda, elektron-safsızlık potansiyel etkileşim enerjisinin olmasıdır. Bu enerji negatif işaretli olmasından dolayı toplam Hamiltoniyende azaltıcı bir etkiye sahiptir.

Bir elektronun safsızlığa bağlanma enerjisi $E_{n l}^{b}=E_{n l}(Z=0)-E_{n l}(Z=1)$ şeklinde tanımlanabilir. Burada $E_{n l}(Z=0)$ safsızlığın olmadığı durumdaki kuantum nokta yapının enerjisini gösterirken, $E_{n l}(Z=1)$ de safsızlığın olduğu durumdaki kuantum nokta yapının enerjisini göstermektedir. Bu durumda elektronun bağlanma enerjisi pozitif olarak ifade edilir. 
Şekil 2'de sonsuz sınırlandırıcı potansiyele sahip kuantum nokta yapının bağlanma enerjilerini yarıçapın fonksiyonu olarak çizdik. Buradan görüleceği üzere aynı enerjide olduğu gibi bağlanma enerjisinin de nokta yarıçapının artmasıyla azaldığı ve sabit değerlere gittiği görülmektedir. Küçük nokta yarıçaplarına giderken, $R \rightarrow 0$, bağlanma enerjinin de hızlı bir şekilde ıraksadığg görülmektedir. Bunun nedeni elektron uzaysal olarak daha dar bir bölgeye hapsedilmesidir. Aynı zamanda Şekil 2'de görüleceği gibi daha dış orbitallere doğru gidildikçe bağlanma enerjisinin değeri azalmaktadır, bu da beklenilen bir durumdur. Yani elektron diş orbitallerde iç (core) elektronlara göre çekirdeğe daha zayıf bağlıdır.
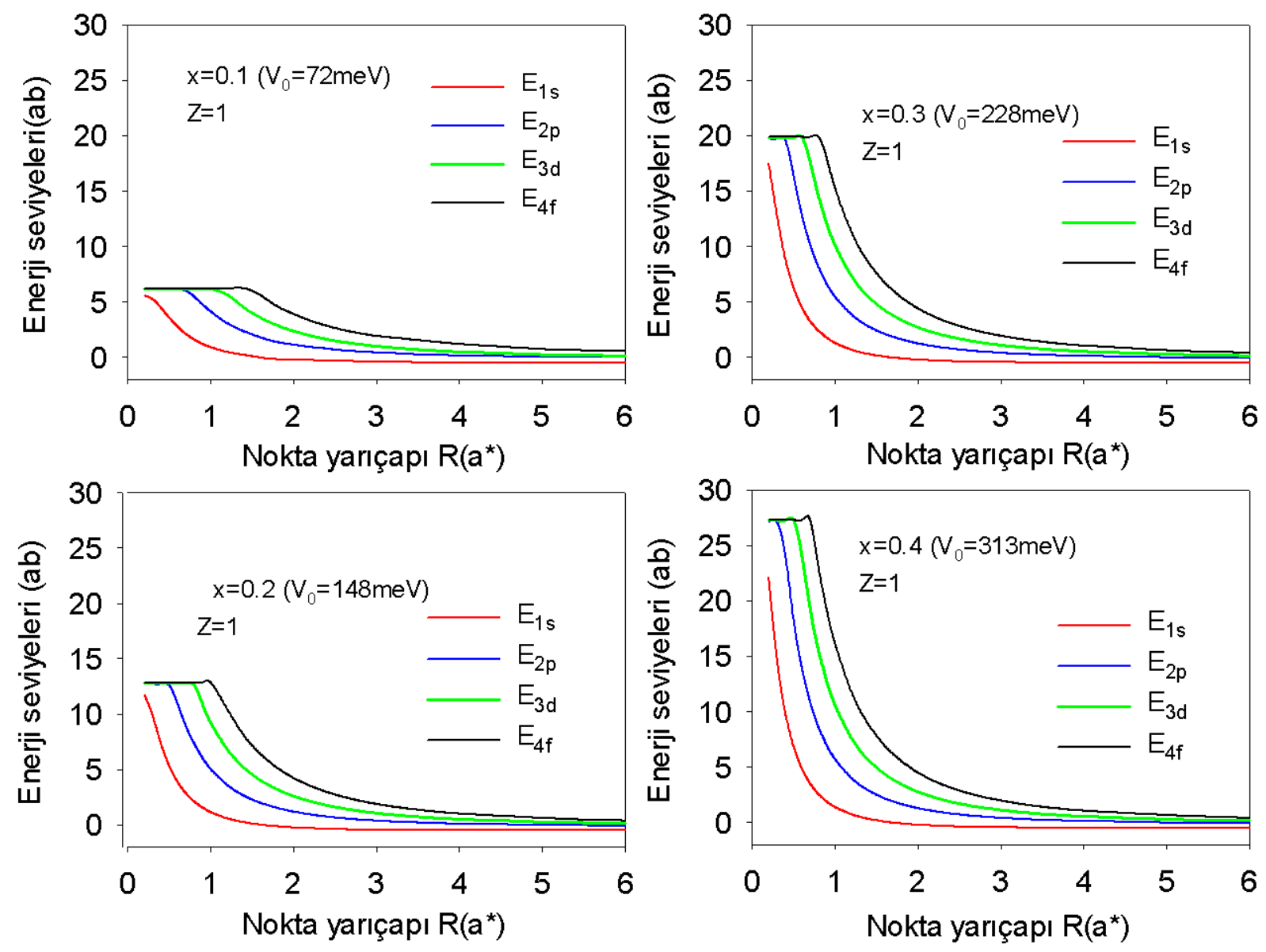

Şekil 3.Kuantum nokta yarıçapının fonksiyonu olarak Al konsantrasyonunun $x$ dört farklı değeri için küresel kuantum nokta yapının $1 \mathrm{~s}, 2 \mathrm{p}, 3 \mathrm{~d}$ ve $4 \mathrm{f}$ seviyelerinin enerjileri

Şekil 3 nokta yarıçapının fonksiyonu olarak sonlu sınırlandırıcı potansiyele sahip küresel kuantum nokta yapının taban ve çeşitli uyarılmış durumlarının enerji seviyeleri dört farklı Al konsantrasyon $x$ değeri için çizilmiştir. Eğrilerden görüleceği gibi nokta yarıçapı artarken beklenildiği gibi tüm enerjiler azalmaktadır. Nokta yarıçapının daha büyük değerlere artırılmasıyla, sistem atom modeline benzeyeceği için, enerji değerleri hidrojen atomunun enerji değerlerine gittiği görülmektedir. Bu durum Tablo 1'de açık şekilde görülebilir. Yani çok büyük nokta yarıçaplarında örneğin $\mathrm{R}=20$ için 1 s seviyesinin enerji değeri -0.5 ab ye, $2 \mathrm{p}$ 
seviyesi $-0.1250 \mathrm{ab}$ değerine yaklaştığı görülmektedir. Aynı şekilde çok daha ileri nokta yarıçaplarında $3 \mathrm{~d}$ ve $4 \mathrm{f}$ seviyelerinin enerjileri de yaklaşık $-0.0538 \mathrm{ab}$ ve $-0.0173 \mathrm{ab}$ olarak bulunmuştur. Bu değerlerde hidrojen atomunun enerji değerlerine karşılık gelmektedir. Şekil 3 'te görüleceği gibi, enerji seviyeleri üzerinde kuyu derinliğinin sınırlandırma etkisi açık bir şekilde görülmektedir.

Tablo 1. Al konsantrasyonu $x=0.2,0.3$ ve 0.4 değeri için sonlu sınırlandırıcı kuantum nokta yapının bazı nokta yarıçaplarında $1 \mathrm{~s}, 2 \mathrm{p}, 3 \mathrm{~d}$ ve $4 \mathrm{f}$ seviyelerinin enerji değerleri. Burada e-t ifadesi $\left(10^{-t}\right)$ ' yi göstermektedir

\begin{tabular}{ccrrrr}
\hline $\boldsymbol{x}$ & $\mathbf{R}$ & \multicolumn{1}{l}{$\boldsymbol{E}_{\mathbf{1} \boldsymbol{s}}$} & \multicolumn{1}{c}{$\boldsymbol{E}_{\mathbf{2} \boldsymbol{p}}$} & \multicolumn{1}{c}{$\boldsymbol{E}_{\mathbf{3} \boldsymbol{d}}$} & \multicolumn{1}{c}{$\boldsymbol{E}_{\boldsymbol{4} \boldsymbol{f}}$} \\
\hline 0.2 & 0.3 & 9.8645 & 12.7200 & 12.8156 & 12.8488 \\
& 0.5 & 5.3482 & 12.6112 & 12.8156 & 12.8488 \\
& 1 & 1.1442 & 5.0420 & 9.2271 & 12.8488 \\
& 2 & -0.2420 & 1.1820 & 2.6012 & 4.2152 \\
& 3 & -0.4454 & 0.3736 & 1.0825 & 1.8724 \\
& 6 & -0.4993 & -0.0644 & 0.1605 & 0.3875 \\
& 10 & -0.5000 & -0.1190 & $-6.6981 \mathrm{e}-3$ & 0.0934 \\
& 20 & -0.5000 & -0.1249 & -0.0539 & -0.0198 \\
0.3 & 0.3 & 12.8825 & 19.7300 & 19.8421 & 19.8806 \\
& 0.5 & 6.2750 & 16.4325 & 19.8421 & 19.8806 \\
& 1 & 1.2868 & 5.4590 & 10.0858 & 15.3023 \\
& 2 & -0.2276 & 1.2359 & 2.7040 & 4.3811 \\
& 3 & -0.4418 & 0.3888 & 1.1128 & 1.9214 \\
& 6 & -0.4994 & -0.0629 & 0.1659 & 0.4137 \\
& 10 & -0.5000 & -0.1170 & $-4.2029 \mathrm{e}-3$ & 0.1023 \\
& 20 & -0.5000 & -0.1249 & -0.0538 & -0.0173 \\
0.4 & 0.3 & 14.9225 & 27.1235 & 27.2591 & 27.3033 \\
& 0.5 & 6.8683 & 18.3714 & 27.2589 & 27.3033 \\
& 1 & 1.3758 & 5.7092 & 10.5690 & 16.1587 \\
& 2 & -0.2183 & 1.2687 & 2.7653 & 4.4793 \\
& 3 & -0.4380 & 0.4041 & 1.1432 & 1.9696 \\
& 6 & -0.4993 & -0.0615 & 0.1689 & 0.4173 \\
& 10 & -0.5000 & -0.1174 & $3.1981 \mathrm{e}-4$ & 0.1116 \\
& 20 & -0.5000 & -0.1250 & -0.0540 & $1.1300 \mathrm{e}-3$ \\
\hline & & & & &
\end{tabular}

Küçük nokta yarıçapında enerjinin maksimum değerleri kuyu derinliğinin büyüklüğüne (Al konsantrasyon oranına) bağlı olarak değişmektedir. Yani nokta yarıçapı azalırken enerji artıyor ve kuyu yüksekliğine karşılık gelen bir limit değere (kritik nokta yarıçapına) yaklaşıyor. Enerjilerin maksimum değeri $\mathrm{V}_{0}$ kuyu derinliği değerine kadar çıkabilmektedir. Diğer taraftan çok büyük nokta yarıçaplarında kuyu potansiyelinin sınırlandırma etkisinin çok zayıfladığı ve enerji seviyeleri üzerinde bir etkisinin olmadığı bu sonuçlardan söylenebilir. 

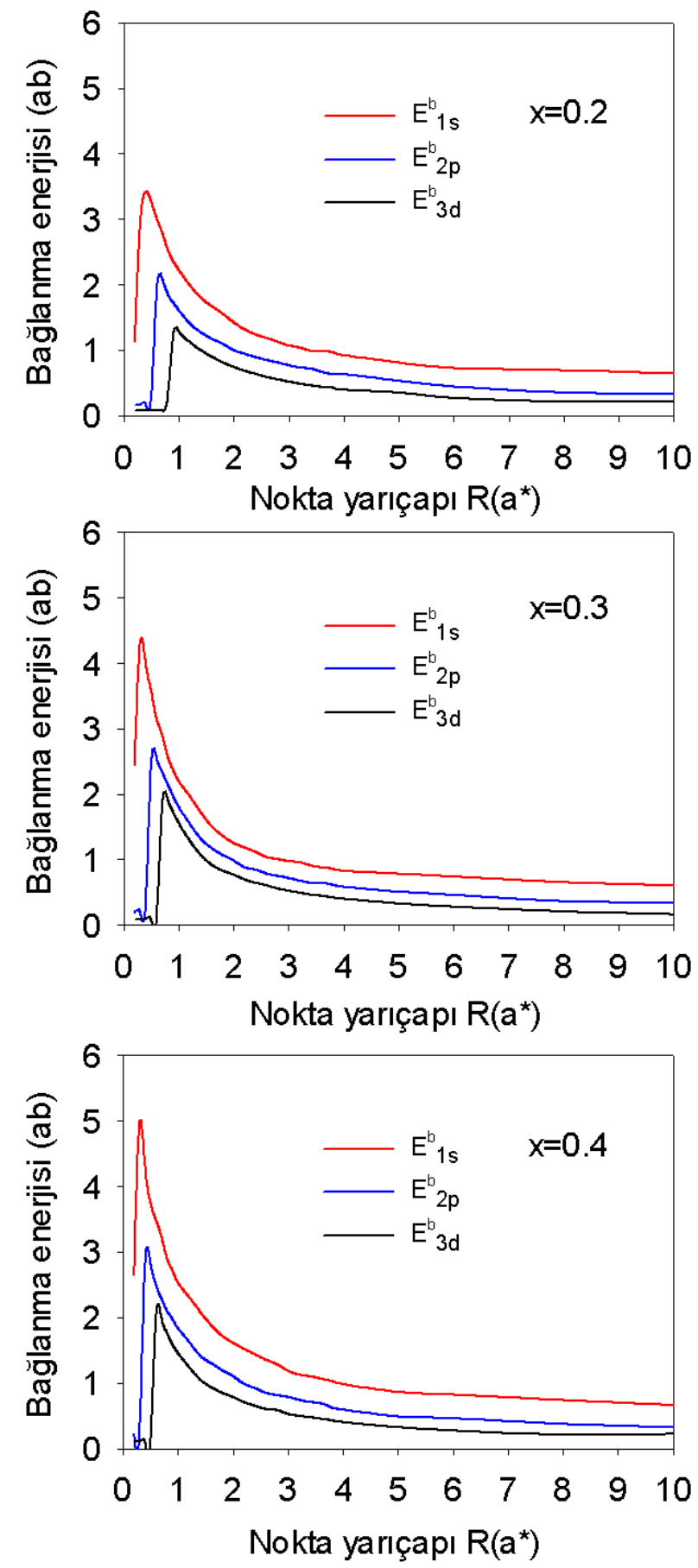

Şekil 4. Nokta yarıçapının fonksiyonu olarak Al konsantrasyonun $x$ 'in üç farklı değeri için küresel kuantum nokta yapının $1 s, 2 p$ ve $3 d$ seviyelerinin bağlanma enerjileri

Şekil 4'te Al konsantrasyonu x'in üç değeri için nokta yarıçapının fonksiyonu olarak küresel kauntum nokta yapının bağlanma enerjilerini çizdik. Şekil 4’ten görüleceği gibi sonlu potansiyel kuyuda safsızlığın bağlanma enerjisi nokta yarıçapı azalırken maksimum değere kadar artıyor ve daha sonra bir limit değere düşüyor. Bu limit değerden sonra kuyuda artık enerji özdeğerleri yoktur. Hâlbuki sonsuz sınırlandırıcı potansiyel durumunda nokta yarıçapı azalırken bağlanma enerjisi artarak ıraksamaktadır. Şekil 4'te kuyu derinliğinin sınırlandırma 
etkisi bağlanma enerjileri üzerinde açık olarak gözükmektedir. Piklerin keskinliği güçlü bir şeklide kuyu derinliğine bağlıdır. Bunun yanında kuyu derinliği arttıkça bağlanma enerjilerinin pik değerleri daha düşük kritik nokta yarıçapına doğru kaydığg görülmektedir. Bu durumun fiziksel nedeni kuyu derinliğin artmasının daha düşük nokta yarıçapında sistemin daha kararlı olduğu şeklinde yorumlanabilir [9].

\section{KAYNAKLAR}

[1] S. Saho, K.X. Guo, Z.H. Zhang, N.Li, C. Peng, Superlatt. Microstruct. 48 (2010) 541.

[2] B. Cakir, A. Ozmen, U. Atav, H. Yuksel, Y. Yakar, Int. J. Mod. Phys. C 18 (2007) 61.

[3] B. Cakir, A. Ozmen, U. Atav, H. Yuksel, Y. Yakar, Int. J. Mod. Phys. C 19 (2008) 599.

[4] Y. Yakar, B. Cakir, A. Ozmen, Int. J. Quant. Chem. 111 (2011) 4139.

[5] Y. Yakar, B. Cakir, A. Ozmen, Philosophical Magazine 95 (2015) 311.

[6] R. Khordad, H. Bahramiyan, International Journal of Modern Physics C 24 (2013) 1350041.

[7] C. Bose, C.K. Sarkar, Phys. Stat. Sol. (b) 218 (2000) 461.

[8] I. Al-Hayek, A.S. Sandouqa, Superlattices Microstructures 85 (2015) 216.

[9] N. Porras-Montenegro, S.T. Perez-Merchancano, Phys. Rev. B 46 (1992) 9780.

[10]E. Sadeghi, Physica E 41 (2009) 1319.

[11] Y. Yakar, B. Cakir, A. Ozmen, Computer Physics Communications 188 (2015) 88.

[12]B. Cakir, Y. Yakar, A. Ozmen, Journal Luminescence 132 (2012) 2659.

[13]B. Cakir, Y. Yakar, A. Ozmen, Physica B 458 (2015) 138.

[14]E.C. Niculescu, D. Bejan, Physica E 74 (2015) 51.

[15]E. Kasapoglu, F. Ungan, C.A. Duque, U. Yesilgul, M. E. Mora-Ramos, H. Sari, I. Sokmen, Physica E 61 (2014) 107.

[16] A. Mandal, S. Sarkar, A.P. Ghosh, M. Ghosh, Chemical Phys. 463 (2015) 149.

[17] S. Saha, S. Pal, J. Ganguly, M. Ghosh, Physica B 484 (2016) 109.

[18]U. Yesilgul, F. Ungan, E.B. Al, E. Kasapoglu, H. Sari, I. Sokmen, Opt. Quant. Electron. 48 (2016) 560.

[19] Y. Yakar, B. Cakir, A. Ozmen J. Lumin. 134 (2013) 778.

[20] A. Ozmen, B. Cakir, Y. Yakar, J. Lumin. 137 (2013) 259.

[21] A. Goyal, I. Kharati, A.K. Singh, M. Mohan, Indian J. Pure and Appl. Phys. 53 (2015) 604.

[22] Y. Yakar, B. Cakir, A. Ozmen, Superlattices and Microstructures 60 (2013) 389.

[23] S. Adachi, GaAs and Related Materials: Bulk Semiconducting and Superlattice Properties (World Scientific, Singapore, 1994). 